\title{
Experimental countermeasures against Ebola virus: current progress and an ethical conundrum
}

\author{
Francis A. Plummer MD LLD, Gary Wong PhD, Gary P. Kobinger PhD
}

$\mathrm{T}$ he administration of what appears to be life-saving serum therapy to two American health volunteers who contracted Ebola in Liberia is a major advance in the treatment of this frequently fatal infection.

This advance is a tribute to the scientists who worked collaboratively across borders for years in the basic research of a treatment for Ebola that eventually resulted in the production of this drug. This advance required many years of working together by a very special type of researcher. Intrepidly, they put their lives on the line daily, whether working in the relatively controlled environment of level-4 laboratories, trapping wild animals in the remote forests of equatorial Africa during a virus-hunting mission or flying off to makeshift high-containment laboratories during filovirus outbreaks. Of note, the latter strategy of bringing a mobile laboratory to the patient has helped enormously in the rapid field diagnosis and isolation of patients with suspected Ebola virus. These researchers are a different breed from the caricature of the "typical" scientist: a bespectacled, studious person in a white coat, manipulating tubes filled with unknown chemicals or injecting mice in the laboratory.

It is also a tribute to the governments that built these very expensive research facilities. These governments provided sustained, longterm funding over many years, without any certain outcome, for a rare infection that occurs in faraway lands, among some of the poorest nations in Africa. Of special note for Canadians is the extensive involvement of Canadian biotechechnology companies, particularly with the development and advance of Ebola vaccines and therapeutics for eventual human use.

Although serum therapy was used frequently in the pre-antibiotic era against a variety of pathogens, ${ }^{1,2}$ the consequences of its use against Ebola infections are potentially far-reaching. These candidate countermeasures in the pipeline against Ebola, and perhaps other viral hemorrhagic fevers, appear promising.

The human-mouse chimeric monoclonal antibody cocktail used in Liberia is one of a growing number of Ebola countermeasures and was developed by collaborators in the Public Health Agency of Canada, the U.S. Army Medical Research Institute of Infectious Diseases, the Toronto-based company Defyrus Inc. and the San Diego-based company Mapp Biopharmaceutical. In addition, two candidate vaccines developed by the National Institutes of Health and the National Microbiology Laboratory are being pushed toward imminent phase I trials. These are the chimpanzee adenovirus and vesicular stomatitis virus gene delivery systems (Vaccine Research Center, National Institutes of Health: unpublished data, 2014). ${ }^{3,4}$ Combinations of biologic agents, such as monoclonal antibodies, ${ }^{5}$ are about to enter phase I clinical trials within the next few months. Customdesigned small interfering RNA, a product of the Vancouver-based company Tekmira Pharmaceuticals Corporation, has been approved by the US Food and Drug Administration for accelerated clinical development.

Funding and regulatory agencies are moving quickly to fast-track the above products through clinical trials, as well as other promising countermeasures against Ebola. Novel methods of protein production (e.g., monoclonal antibodies) in tobacco plants are being pursued ${ }^{6}$ and offer a means for the rapid, economical and large-scale production of a desired protein.

The administration of Ebola antibodies in humans raises some difficult and thorny ethical issues. When there are only two doses available and thousands are in need, who gets the treatment? Two volunteer health care workers who

\section{KEY POINTS}

- There are several Ebola countermeasures in development that are being fast-tracked through clinical trials.

- One of these therapies, a human-mouse chimeric monoclonal antibody combination, has already been used successfully in two patients.

- Situations in which demand far exceeds supply are frequent during the early development of vaccines and therapeutics and raise difficult ethical issues.

- Vaccines, such as the two currently being pushed toward imminent phase I trials, may be useful in controlling outbreaks. 
put their lives on the line to help Liberians during an uncontrolled, unprecedented outbreak, or two of the hundreds of Africans who might benefit from an experimental, nonapproved treatment?

In this situation, two Americans received the treatment and may have been saved by it. These situations in which demand far exceeds supply are frequent during the early development of vaccines and therapeutics. The Americans ultimately received the antibodies because of access: access to the networks that could obtain the treatment, access to the treatment itself and access to rapid and tailored transportation.

If the two Americans had not received the drug, then who should have? It could have been administered to two infected Liberians selected through lottery or some other perceived or accepted equitable means. How would you handle this in the context of an extreme shortage of treatment?

Another side of this issue is the compassionate use of an experimental treatment in humans. The antibody cocktail used in the two Americans had not been through a full regulatory evaluation for safety and efficacy. Although partially mitigated by the safe use of serum therapy in the past, as well as the good safety records of monoclonal antibody-based treatments against a variety of human conditions and ailments, ${ }^{7}$ the risk of plantmade monoclonals in human recipients is unknown. The adverse effects could have been severe, even deadly. If the antibodies were used on two Africans and had resulted in fatality or other treatment-associated negative outcomes, the outcry and recriminations would have been deafening and would likely have negatively affected international relief efforts aimed at helping the local African populace during this outbreak.

In the absence of funding and resources from the US and Canadian players involved, it is important to note that these antibodies may not have been developed in the first place, and then no one would have received this treatment. Thus, despite the difficult ethical questions that abound in this situation, two lives may have been saved, these antibodies did not appear to cause severe adverse effects in these limited human cases and Ebola science was advanced.

What comes next? In addition to accelerating the progress of candidate Ebola vaccines from bench to bedside, we need further research on Ebola pathogenesis, the identification of the reservoir animal species for Ebola virus and the mechanisms of action behind this novel antibody-based therapy. This treatment may also usher in a new era of serum therapy for certain infectious diseases, particularly viral hemorrhagic fevers. The rush to trial of vaccine candi- dates, which had previously been moving along slowly, will likely yield preventive vaccines that are more applicable to controlling outbreaks. In the realm of possibilities, an important one is that more lives will be saved as a consequence, direct or indirect, of the unfolding events.

The near future promises to deliver new options for the prevention and treatment of Ebola virus. This needs to be the last natural Ebola outbreak during which efficacious and safe clinical options are still not widely available.

\section{References}

1. Simon C. An introduction to the study of infection and immunity including chapters or serum therapy, vaccine therapy, chemotherapy and serum diagnosis. Philadelphia (PA): Lea and Febiger; 2013.

2. Reimann H. The pneumonias. Philadelphia (PA): WB Saunders; 1938.

3. Jones SM, Feldmann H, Ströher U, et al. Live attenuated recombinant vaccine protects nonhuman primates against Ebola and Marburg viruses. Nat Med 2005;11:786-90.

4. Kobinger GP, Feldmann H, Zhi Y, et al. Chimpanzee adenovirus vaccine protects against Zaire Ebola virus. Virology 2006; 346:394-401.

5. Qiu X, Wong G, Fernando L, et al. mAbs and Ad-Vectored IFN-alpha therapy rescue Ebola-infected nonhuman primates when administered after the detection of viremia and symptoms. Sci Transl Med 2013;5:207ra143.

6. Giritch A, Marillonnet S, Engler C, et al. Rapid high-yield expression of full-size IgG antibodies in plants coinfected with noncompeting viral vectors. Proc Natl Acad Sci U S A 2006;103: 14701-6.

7. Reichert JM, Rosensweig CJ, Faden LB, et al. Monoclonal antibody successes in the clinic. Nat Biotechnol 2005;23:1073-8.

Competing interests: Gary Kobinger has been involved in the testing and/or development of Ebola vaccines based on DNA, adeno-associated viruses, adenoviruses, virus-like particles, vesicular stomatitis virus, parainfluenza and rabies, as well as treatments for Ebola based on or using dextrose $5 \%$, ringer lactate, corticosteroids, anticoagulants, antibodies, vesicular stomatitis virus, nicotine, adenovirus, interferons and IMT504. Gary Wong has been involved in the testing and/or development of Ebola vaccines based on adenovirus, DNA and vesicular stomatitis virus, and treatments for Ebola using 5\% dextrose, ringer lactate, corticosteroids, anticoagulants, antibodies, vesicular stomatitis virus, adenovirus and interferon. None declared for Francis Plummer.

Affiliations: National Microbiology Laboratory (Plummer, Kobinger), Public Health Agency of Canada; Department of Medical Microbiology (Plummer, Wong, Kobinger), University of Manitoba; Department of Immunology (Kobinger), University of Manitoba, Winnipeg, Man.; Department of Pathology and Laboratory Medicine (Kobinger), University of Pennsylvania School of Medicine, Philadelphia, Pa.

Contributors: Francis Plummer and Gary Kobinger analysed the ethical questions for this commentary. Gary Kobinger performed the literature analysis. Gary Wong conducted the literature research and review and an indepth review of the commentary. Francis Plummer is the primary author of the commentary.

For resources on Ebola for clinicians, see www.cmaj .ca/site/misc/ebola.xhtml. The Ebola page includes links to relevant $C M A J$ articles and key national and international resources. 